\title{
KAJIAN IKLIM MIKRO DI BAWAH TEGAKAN RUANG TERBUKA HIJAU UNIVERSITAS LAMPUNG
}

\section{(STUDY OF MICROCLIMATE UNDER GREEN OPEN SPACE STANDS UNIVERSITY OF LAMPUNG)}

\author{
Sapariyanto $^{1}$, Slamet Budi Yuwono ${ }^{1}$, dan Melya Riniarti ${ }^{2}$ \\ Jurusan Kehutanan Fakultas Pertanian Universitas Lampung \\ J1. Sumatri Brojonegoro No 1 Bandarlampung. 35145 \\ E-mail: Sapariyanto08@gmail.com \\ No. Telepon: 085841089547
}

\begin{abstract}
ABSTRAK
Universitas Lampung memiliki ruang terbuka hijau cukup luas dengan vegetasi yang beragam.Keberadaan ruang terbuka hijau memiliki manfaat yang cukup besar dalam pengendalian suhu dan kelembaban udara.Penelitian ini bertujuan untuk mengetahui pengaruh vegetasi di ruang terbuka hijau terhadap suhu, kelembaban udara, tingkat kenyamanan dan estetika.Penelitian ini menggunakan model rancangan acak kelompok lengkap dengan teknik Purposive sampling dan wawancara yang dilaksanakan pada bulan Februari 2015. Hasil dari penelitian menunjukkan bahwa suhu udara tertinggi pada pagi, siang dan sore hari adalah di lokasi lapangan sepak bola. Suhu udara terendah pada pagi, siang dan sore hari adalah di lokasi tegakan campuran. Kelembaban udara tertinggi pada pagi hari adalah di lokasi tegakan beringin, sedangkan siang dan sore hari berada di lokasi tegakan sengon buto. Kelembaban udara terendah pada pagi, siang dan sore hari berada di lokasi lapangan sepak bola. Berdasarkan indek suhu dan kelembaban (THI) lokasi lapangan sepak bola, tegakan sengon buto, tegakan beringin dan tegakan campuran termasuk dalam kategori tidak nyaman.Persepsi responden terhadap tingkat kenyamanan dan keindahan ruang terbuka hijau di lokasi lapangan sepak bola termasuk dalam kategori tidak nyaman dan kurang indah.Lokasi tegakan sengon buto, tegakan beringin dan tegakan campuran termasuk dalam kategori nyaman dan indah.
\end{abstract}

Kata kunci: iklim mikro, kenyamanan, ruang terbuka hijau

\section{ABSTRACT}

University of Lampung has quite extensive green open space with the diversity of vegetation. The presence of green open space consider to have benefits to control the temperature and humidity. This research was aimed to know the influence of vegetation on the green open space to control temperature, humidity, the degree of comfort and aesthetics. This study used randomized group complete design model with purposive sampling techniques and interviews which conducted on February 2015. The results of this research showed that the highest air temperature in the morning, noon and evening were in the football field. The lowest temperature in the morning, noon and evening were in mixed forest stands. The highest humidity in the morning was in Ficus benjamina stands, while in the afternoon and evening were in Enterolobium cyclocarpum stands. The lowest air humidity in the morning, noon and late afternoon were in thefootball field. Based on the temperature and humidity index (THI) the football field, Enterolobium cyclocarpum stands, Ficus benjamina stands and mixed forest stands were included in the uncomfortable category. Based on perception of repondens towards the comfort level and green open space aesthetic, the football field categoried as 
uncomfortable and less aesthetic. While, Enterolobium cyclocarpum stands, Ficus benjamina stands and mixed forest stands categoried as comfortable and aesthetic.

Keywords: comfort, micro-climate, open green space

\section{PENDAHULUAN}

Ruang terbuka hijau (RTH) merupakan suatu bentuk pemanfaatan lahan pada suatu kawasan yang diperuntukan untuk penghijauan.Fungsi ekologis RTH yaitu menciptakan iklim mikro yang nyaman, menyerap air hujan dan memelihara ekosistem.Semakin banyak jumlah dan jenis tanaman yang terdapat di dalam suatu RTH, maka semakin meningkat kemampuan RTH dalam menanggulangi permasalahan lingkungan.Selain itu, keberadaan vegetasi dalam RTH dapat mempengaruhi kondisi iklim mikro, seperti suhu udara, kelembaban udara dan radiasi matahari.

Universitas Lampung yang dikenal dengan sebutan kampus hijau (Green Campus) memiliki RTH yang lebih luas dari ruang terbangun dengan tipe vegetasi beragam yang tersebar.Keberadaan RTH di Universitas Lampung diharapkan mempengaruhi dua aspek penting, yaitu aspek estetika dan aspek kenyamanan.Aspek estetika suatu RTH yaitu sebagai sarana penunjang keindahan kampus dan sarana pembingkai pemandangan untuk melembutkan kesan kaku dari bangunan kampus. Menurut Gunawan (2005), kondisi vegetasi RTH yang baik mampu memperbaiki iklim mikro kota, sehingga masyarakat merasa nyaman untuk beraktivitas di dalam maupun di sekitar.

Perlu diketahui seberapa besar pengaruh RTH yang ada di Universitas Lampung terhadap suhu dan kelembaban udara.Tujuan penelitian ini adalah menganalisis pengaruh vegetasi pada ruang terbuka hijau terhadap suhu dan kelembaban, tingkat kenyamanan dan estetika.

\section{METODE PENELITIAN}

Penelitian ini dilakukan di empat RTH Universitas Lampung(Gambar 1)Lokasi RTH ada di lapangan sepak bola Universitas Lampung, tegakan dominan sengon buto (Enterolobium cyclocarpum)yang berada di arboretum Perpustakaan, tegakan beringin (Ficus benjamina)berada di depan Gedung Rektorat Lama dan tegakan campuran berada di Arboretum Pertanian. Penelitian dilaksanakan pada Bulan Februari 2015.Alat-alat yang digunakan dalam penelitian ini adalah kamera, alat tulis, komputer, termometer digital dan higrometer.Bahan yang digunakan dalam penelitian ini adalah tegakan pohon dan kuisioner. 


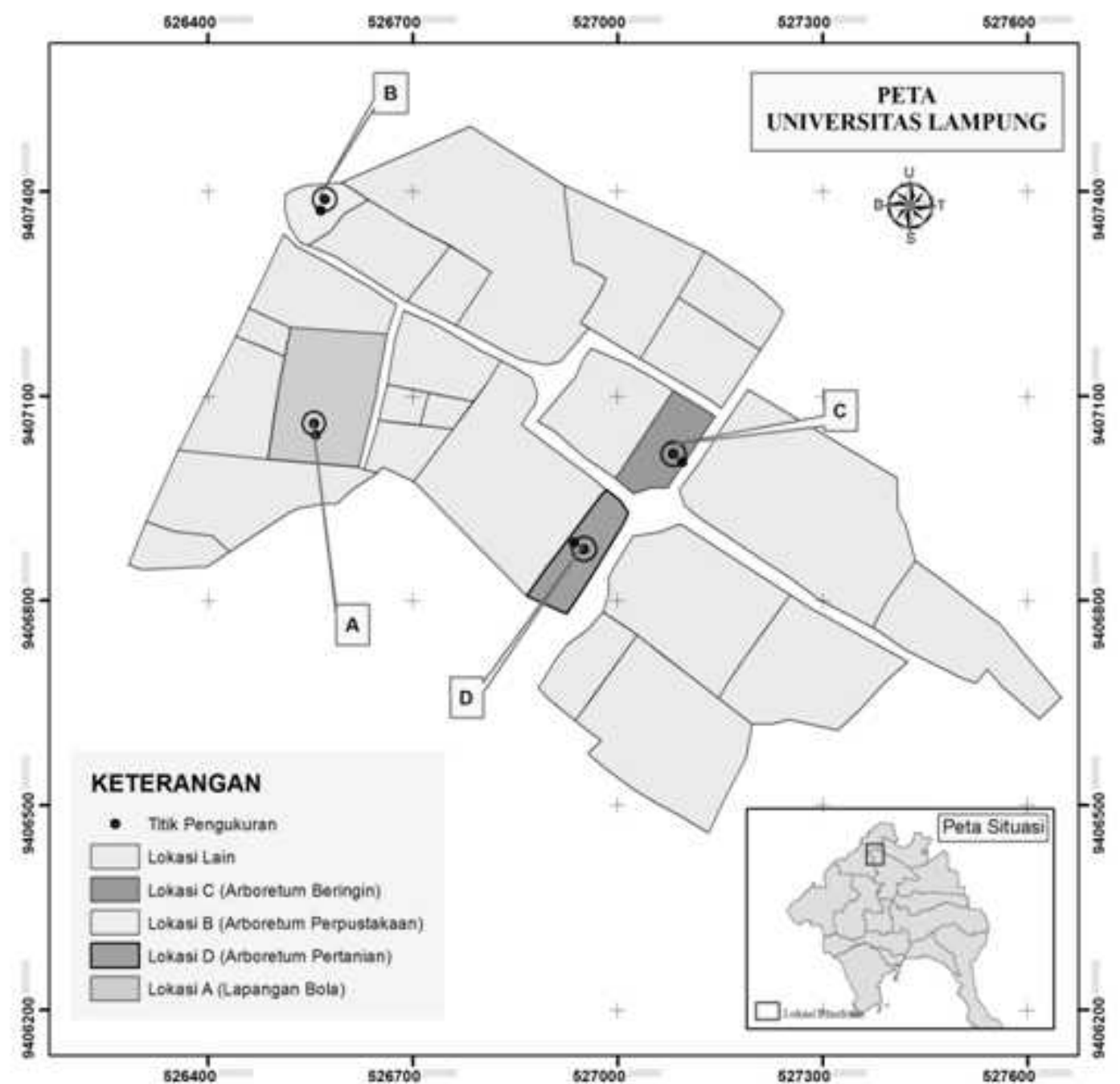

Gambar 1. Peta Universitas Lampung

Dataprimer yang dikumpulkan langsung dari hasil pengukuran di lapangan yaitu data suhu udara, kelembaban udara,persepsi responden dan analisis vegetasi (kerapatan pohon dan luas tajuk).Penelitian menggunakan Rancangan Acak Kelompok Lengkap (RAKL) dengan teknik Purposive sampling yaitu dalam pengambilan sampel didasarkan pada karakteristik tertentu. Pengambilan sampel didasarkan pada karakteristik yang sesuai dengan tujuan penelitian. Pengukuran suhu dan kelembaban dilakukan selama 15 hari, pada pagi hari pukul 08.00 - 09.00, siang hari pukul 12.00 - 13.00 dan sore hari pukul 16.00 - 17.00sebanyak lima ulangan disetiap lokasinya. Untuk mengetahui persepsi responden terhadap tingkat kenyamanan dan estetika dilakukan wawancara secara langsung dengan menggunakan daftar pertanyaan. Berdasarkan rumus Arikunto (2011), jumlah responden yang diwawancarai sebanyak 154 responden.

Data suhu dan kelembaban udara yang sudah diperoleh dari hasil pengukuran diolah dengan menggunakan Microsoft office excel kemudian dianalisis uji homogenitas, uji anova dan uji beda nilai tengah (BNT) menggunakan SPSS statistic 17.0. Analisis kenyamanan lingkungan berdasarkan indek suhu kelembaban (THI) pada setiap lokasi dengan rumus Niewolt dalam Wirasasmita (2003), adalah:THI $=0.8 \mathrm{~T}+(\mathrm{RH} \times \mathrm{T}) / 500$

Keterangan : $\mathrm{T}=$ suhu udara.

$$
\text { RH }=\text { kelembaban udara. }
$$


Wirasasmita (2003), menyatakan bahwa indeks kenyamanan dapat dibedakan menjadi tiga kondisi yaitu, kondisi nyaman dengan nilai THI 19 - 23, kondisi sedang nilai THI 23 - 27 dan nilai THI > 27 dinyatakan yang tidak nyaman.Hasil wawancara dengan responden ditabulasi dan dianalisis untuk melihat persepsi responden terhadap kenyamanan RTH.

\section{HASIL DAN PEMBAHASAN}

\section{Hasil}

\section{Kondisi vegetasi RTH di Universitas Lampung}

Terdapat empat RTH di Universitas Lampung yang dijadikan lokasi pengambilan data iklim mikro.Keempat lokasi tersebut adalah lapangan sepak bola, tegakan yang didominasi pohon sengon buto, tegakan beringin dan tegakan campuran (Tabel 1).Lokasi lapangan sepak bola digunakan sebagai lokasi kontrol atau pembanding dengan lokasi yang bervegetasi pohon.Lapangan sepak bola tidak terdapat vegetasi pohon, hanya terdapat rumput.

Tabel 1. Kerapatan pohon dan luas tajuk keempat RTH di Universitas Lampung.

\begin{tabular}{lrlr}
\hline Lokasi & $\begin{array}{l}\text { Jumlah } \\
\text { pohon }\end{array}$ & $\begin{array}{l}\text { Kerapatan pohon } \\
\text { (pohon/ha) }\end{array}$ & $\begin{array}{l}\text { Luas tajuk } \\
\text { Pohon }\left(\mathrm{m}^{2} / \mathrm{ha}\right)\end{array}$ \\
\hline Lapangan sepak bola & 0 & 0 & 0,00 \\
Tegakan sengon buto & 19 & 147 & $3.425,51$ \\
Tegakan beringin & 1 & 8 & $1.162,50$ \\
Tegakan campuran & 38 & 293 & $1.903,53$ \\
\hline
\end{tabular}

Sumber: Data primer 2015

Pada lokasi tegakan yang didominasi pohon sengon buto terdapat 19 pohon dalam plot berukuran 0,13 ha. Sepuluh diantaranya adalah pohon sengon buto yang memiliki sistem percabangan dikotom. Pada lokasi ini terdapat empat jenis pohon lainnya yaitu jati, durian, wareng, dan salam. Keempat pohon tersebut memiliki sistem percabangan simpodial.

Lokasi tegakan beringin dengan luas pengamatan 0,13 ha, hanya ada satu pohon. Pohon ini memiliki sistem percabangan monopodial dengan bentuk batang tegak lurus dan bentuk tajuk tebal bulat.Lokasi tegakan beringin meskipun hanya satu pohon, tetapi memiliki tajuk yang luas.Lokasi tegakan campuran berada di Arboretum Fakultas Pertanian.Pada lokasi ini terdapat 38 pohon. Ada lima jenis pohon pada tegakan campuran, yaitu mahoni, salam, sengon buto, tangkil dan wareng. Hasil pengamatan menunjukkan bahwa lokasi tegakan campuran memiliki kerapatan pohon tertinggi bila dibandingkan dua lokasi lain.

\section{Suhu udara dan kelembaban udara}

Hasil analisis ragamsuhu udara pada pagi, siang dan sore hari dapat dilihat pada Tabel

2. Hasil analisis menunjukkan bahwa keempat lokasi memiliki perbedaan suhu yang nyata.

Tabel 2. Hasil analisis ragam untuk parameter suhu udara pada pagi, siang dan sore hari.

\begin{tabular}{|c|c|c|c|}
\hline \multirow{2}{*}{ Sumber keragaman } & \multicolumn{3}{|c|}{$F_{\text {hitung }}$} \\
\hline & Pagi hari & Siang hari & Sore hari \\
\hline Kelompok & $36,06^{*}$ & $153.14 *$ & $124,72 *$ \\
\hline Ulangan & $4,01 *$ & $1,12^{\mathrm{ns}}$ & $3,98^{*}$ \\
\hline$F_{\text {tabel }}(\alpha 0.05)$ & 2,02 & 2,02 & 2,02 \\
\hline
\end{tabular}

Sumber: Data olah statistik 2016 
Keterangan: angka yang ditandai (*) berarti lokasi berpengaruh nyata pada taraf $5 \%$. angka yang ditandai $\left({ }^{\mathrm{ns}}\right)$ berarti lokasi tidak berpengaruh nyata pada taraf $5 \%$.

Hasil analisis ragam kelembaban udara pada pagi, siang dan sore hari dapat dilihat pada Tabel 3. Hasil analisis menunjukkan bahwa keempat lokasi tidak berbeda nyata pada pagi hari.Tetapi, pada siang dan sore hari keempat lokasi memiliki kelembaban udara yang berbeda nyata.

Tabel 3.Rekapitulasi analisis ragam untuk parameter penelitian kelembaban udara.

\begin{tabular}{lrrr}
\hline \multirow{2}{*}{ Sumber keragaman } & \multicolumn{3}{c}{$\mathrm{F}_{\text {hitung }}$} \\
\cline { 2 - 4 } & Pagi hari & Siang hari & Sore hari \\
\hline Kelompok & $0,47^{\mathrm{ns}}$ & $47,61^{*}$ & $100,88^{*}$ \\
Ulangan & $3,31^{*}$ & $2,63^{\mathrm{ns}}$ & $2,42^{*}$ \\
$\mathrm{~F}_{\text {tabel }}(\alpha 0.05)$ & 2,02 & 2,02 & 2,02 \\
\hline
\end{tabular}

Sumber: Data olah statistik 2016

Keterangan: angka yang ditandai $(*)$ berarti lokasi berpengaruh nyata pada taraf $5 \%$. angka yang ditandai $\left({ }^{\mathrm{ns}}\right)$ berarti lokasi tidak berpengaruh nyata pada taraf $5 \%$.

Hasil uji BNT suhu udara pada pagi, siang dan sore hari dapat dilihat pada Tabel 4. Pada pagi, siang dan sore hari, lokasi lapangan sepak bola memiliki suhu udara tertinggi dari ketiga lokasi lain. Lokasi tegakan campuran memiliki suhu udara terendah dari ketiga lokasi lain pada pagi, siang maupun sore hari.

Tabel 4. Rata-rata suhu udara $\left({ }^{0} \mathrm{C}\right)$ pagi, siang dan sore hari di keempat RTH Universitas Lampung.

\begin{tabular}{lccr}
\hline \multirow{2}{*}{ Lokasi } & \multicolumn{3}{c}{ Suhu udara $\left({ }^{0} \mathrm{C}\right)$} \\
\cline { 2 - 4 } & Pagi hari & Siang hari & Sore hari \\
\hline Lapangan sepak bola & $25,20^{\mathrm{a}}$ & $32,04^{\mathrm{a}}$ & $29,06^{\mathrm{a}}$ \\
Tegakan sengon buto & $24,71^{\mathrm{b}}$ & $28,83^{\mathrm{b}}$ & $27,54^{\mathrm{b}}$ \\
Tegakan beringin & $24,36^{\mathrm{c}}$ & $28,51^{\mathrm{bc}}$ & $27,64^{\mathrm{b}}$ \\
Tegakan campuran & $24,10^{\mathrm{d}}$ & $28,28^{\mathrm{c}}$ & $27,45^{\mathrm{b}}$ \\
\hline BNT $(\alpha: 0,05)$ & 0,22 & 0,41 & 0,19 \\
\hline
\end{tabular}

Sumber: Data olah statistik 2016

Keterangan: Nilai yang diikuti huruf yang sama berarti tidak berbeda nyata.

Hasil uji BNT kelembaban udara pada siang dan sore hari dapat dilihat di Tabel 5.Kelembaban udara siang hari di keempat lokasi memiliki perbedaan kelembaban udara yang nyata.Pada sore hari, kelembaban udara pada tegakan beringin tidak berbeda nyata dengan tegakan campuran.

Tabel 5. Rata-rata kelembaban udara (\%)di keempat RTH Universitas Lampung.

\begin{tabular}{lcr}
\hline \multirow{2}{*}{ Lokasi } & \multicolumn{2}{c}{ Kelembaban udara $(\%)$} \\
\cline { 2 - 3 } & Siang hari & Sore hari \\
\hline Lapangan sepak bola & $75,08^{\mathrm{d}}$ & $76,49^{\mathrm{c}}$ \\
Tegakan sengon buto & $82,71^{\mathrm{a}}$ & $83,24^{\mathrm{a}}$ \\
Tegakan beringin & $77,75^{\mathrm{c}}$ & $81,28^{\mathrm{b}}$ \\
Tegakan campuran & $79,88^{\mathrm{b}}$ & $80,87^{\mathrm{b}}$ \\
\hline BNT $(\alpha: 0,05)$ & 1,34 & 1,26 \\
\hline
\end{tabular}

Sumber: Data olah statistik 2016 
Keterangan: Nilai yang diikuti huruf yang sama artinya tidak berbeda nyata.

Kenyamanan berdasarkan nilai THI (Themperature Humidity Index).

Hasil analisis THI dapat dilihat pada Tabel 8. Kenyamanan lingkungan pada siang hari di Universitas Lampung dari keempat lokasi termasuk dalam kategori tidak nyaman.Nilai THI pagi hari lokasi lapangan sepak bola, tegakan sengon buto, tegakan beringin dan tegakan campuran masuk dalam kategori sedang/cukup nyaman.Sementara, pada siang hari keempat lokasi tersebut masuk dalam kategori tidak nyaman.Nilai THI pada sore hari hanya lokasi lapangan sepak bola yang masuk dalam kategori tidak nyaman, sedangkan ketiga lokasi lainnya termasuk dalam kategori sedang/cukup nyaman.

Tabel 8. Nilai THI (Themperature Humidity Index) di empat RTH Universitas Lampung.

\begin{tabular}{|c|c|c|c|c|c|}
\hline \multirow[b]{2}{*}{ Lokasi } & \multicolumn{3}{|c|}{ Faktor THI } & \multirow[b]{2}{*}{$\begin{array}{l}\text { Nilai } \\
\text { THI }\end{array}$} & \multirow[b]{2}{*}{ Keterangan } \\
\hline & $\begin{array}{l}\text { Waktu pengambilan } \\
\text { data }\end{array}$ & $\begin{array}{l}\text { Suhu Udara } \\
\left({ }^{0} \mathrm{C}\right)\end{array}$ & $\begin{array}{l}\text { Kelembaban } \\
\text { Udara }(\%)\end{array}$ & & \\
\hline \multirow{3}{*}{$\begin{array}{l}\text { Lapangan } \\
\text { sepak bola }\end{array}$} & Pagi & 25,20 & 88,87 & 24,64 & Sedang \\
\hline & Siang & 32,04 & 75,08 & 30,44 & Tidak nyaman \\
\hline & Sore & 29,06 & 76,49 & 27,69 & Tidak nyaman \\
\hline \multirow{3}{*}{$\begin{array}{l}\text { Tegakan } \\
\text { sengon buto }\end{array}$} & Pagi & 24,71 & 89,33 & 24,18 & Sedang \\
\hline & Siang & 28,83 & 82,71 & 27,83 & Tidak nyaman \\
\hline & Sore & 27,54 & 83,24 & 26,62 & Sedang \\
\hline \multirow{3}{*}{$\begin{array}{l}\text { Tegakan } \\
\text { beringin }\end{array}$} & Pagi & 24,36 & 89,39 & 23,84 & Sedang \\
\hline & Siang & 28,51 & 77,75 & 27,24 & Tidak nyaman \\
\hline & Sore & 27,64 & 81,28 & 26,61 & Sedang \\
\hline \multirow{3}{*}{$\begin{array}{l}\text { Tegakan } \\
\text { campuran }\end{array}$} & Pagi & 24,10 & 89,16 & 23,58 & Sedang \\
\hline & Siang & 28,28 & 79,88 & 27,14 & Tidak nyaman \\
\hline & Sore & 27,45 & 80,87 & 26,40 & Sedang \\
\hline
\end{tabular}

Sumber: Data primer 2015

\section{Kenyamanan dan estetika berdasarkan persepsi responden.}

Hasil analisis responden (Tabel 9) terhadap tingkat kenyamanan dan estetika diperoleh dari 154 responden. Responden sebagian besar adalah mahasiswa Universitas Lampung dengan rentang usia 20-23 tahun. Data hasil kuisioner dianalisis menurut persentase tertinggi di tiap variabel.Lokasi yang paling tidak nyaman dan kurang indah berdasarkan persepsi responden berada di lokasi lapangan sepak bola.

Tabel 9. Penilaian responden untuk kenyamanan pada empat RTH Universitas Lampung.

\begin{tabular}{lrrrrr}
\hline \multirow{2}{*}{ Lokasi } & \multicolumn{2}{c}{ Kenyamanan $(\%)$} & \multicolumn{2}{c}{ Estetika $(\%)$} & \multirow{2}{*}{\begin{tabular}{r} 
Total \\
\cline { 2 - 5 }
\end{tabular}} \\
\cline { 2 - 5 } & Nyaman & $\begin{array}{r}\text { Tidak } \\
\text { nyaman }\end{array}$ & Indah & $\begin{array}{r}\text { Kurang } \\
\text { indah }\end{array}$ & $\begin{array}{r}(\%) \\
\text { Lapangan sepak bola }\end{array}$ \\
Tegakan sengon buto & 21,05 & 78,95 & 15,79 & 84,21 & 100,00 \\
Tegakan beringin & 95,13 & 4,87 & 94,88 & 5,12 & 100,00 \\
Tegakan campuran & 89,74 & 10,26 & 90,24 & 9,76 & 100,00 \\
\hline
\end{tabular}

Sumber: Data primer 2015 


\section{Pembahasan}

\section{Suhu udara}

Hasil penelitian menunjukkan bahwa suhu udara pada pagi, siang dan sore hari di empat lokasi RTH berbeda nyata. Hal ini berarti kondisi vegetasi di empat lokasi memiliki pengaruh berbeda dalam mengendalikan suhu udara. Suhu udara di lapangan sepak bola pada pagi, siang dan sore hari tertinggi bila dibandingkan dengan lokasi lain. Hal ini disebabkan di lapangan sepak bola penutup lahan berupa rumput, sehingga tidak ada vegetasi yang berupa pohon yang dapat menyerap sinar matahari.Kondisi vegetasi pada RTH ini menyebabkan terjadinya peningkatan suhu. Suhu vegetasi di atas permukaan terbuka akan lebih tinggi bila dibandingkan dengan suhu di bawah naungan karena radiasi matahari yang diterima oleh tanaman tidak dipantulkan kembali (Lakitan, 2002).

Lokasi tegakan campuran memiliki suhu udara pada pagi, siang dan sore hari, terendah dibandingkan ketiga lokasi lain. Tegakan campuran memiliki kerapatan pohon tertinggi dibandingkan dengan lokasi lain. Kondisi dan jumlah vegetasi pada tegakan campuran berbeda dengan tegakan sengon buto dan tegakan beringin. Lokasi tegakan campuran memiliki kerapatan pohon sebesar 292,31 pohon/ha dan luas tajuk sebesar $1.903,53 \mathrm{~m}^{2} / \mathrm{ha}$ dari 0,13 ha, menyebabkan suhu di lokasi tegakan campuran menjadi rendah.

Adanya hubungan kondisi RTH yang baik yang berada di tegakan campuran dengan penurunan suhu udara disekitar RTH dikarenakan adanya proses fisiologis tumbuhan yang berupa transpirasi. Lakitan (2002), menjelaskan bahwa penyerapan energi matahari oleh sistem tajuk tanaman akan memacu tumbuhan untuk meningkatkan laju transpirasinya (terutama untuk menjaga stabilitas suhu tumbuhan). Menurut Lakitan (1993), pada proses transpirasi tumbuhan akan menggunakan sebagian besar air yang berhasil diserap dari tanah. Tumbuhan akan lebih cepat bertranspirasi jika suhu udaranya tinggi. Hal ini dikarenakan naiknya suhu akan menambah tekanan uap di dalam daun dan juga menambah tekanan uap di luar daun, akan tetapi tekanan yang ada di luar daun tidak setinggi tekanan yang ada di luar daun.

Proses transpirasi akan meningkatkan jumlah uap air di udara. Setiap gram air yang diuapkan akan menggunakan energi sebesar 580 kalori. Karena besarnya energi yang digunakan untuk menguapkan air pada proses transpirasi ini, maka hanya sedikit panas yang tersisa yang akan diteruskan ke bawah tegakan. Hal inilah yang menyebabkan adanya pengaruh vegetasi terhadap suhu udara.Selain itu, jenis, kerapatan dan strata tanaman juga berpengaruh terhadap suhu udara (Scudo, 2002).

\section{Kelembaban udara}

Vegetasi pohon pada RTH memiliki pengaruh cukup besar terhadap iklim mikro.Pohon mampu menyerap radiasi matahari, memberi naungan, dan melakukan transpirasi sehingga dapat menurunkan suhu udara dan meningkatkan kelembaban udara. Menurut Scudo (2002), terdapat beberapa karakteristik struktur pohon yang dapat mempengaruhi iklim mikro antar lain bentuk tajuk, penanaman, ukuran tanaman, dan kepadatan tajuk.

Pada siang dan sore hari kelembaban udara tertinggi berada di lokasi tegakan sengon buto.Vegetasi di tegakan sengon buto memiliki kelembaban yang tinggi disebabkan lokasi ini memiliki tajuk yang paling luas.Luas tajuk pada lokasi tegakan sengon buto adalah 3.425,51 $\mathrm{m}^{2} /$ ha. Perbedaan luas penutup lahan ini yang menyebabkan kelembaban udara yang berada di tegakan sengon buto lebih tinggi daripada di tegakan beringin dan tegakan campuran. Hal ini terjadi karena dengan luasnya penutupan lahan maka akan meningkatkan radiasi matahari dan menghasilkan $\mathrm{H}_{2} \mathrm{O}$. Hasil peningkatan $\mathrm{H}_{2} \mathrm{O}$ dan penyerapan $\mathrm{CO}_{2}$ ini yang akan mempengaruhi peningkatan kelembapan udara (Tauhid, 2008). 
Faktor lain yang menyebabkan RTH di lokasi tegakan sengon buto memiliki kelembaban lebih tinggi dibandingan RTH di lokasi tegakan beringin dan tegakan campuran dikarenakan tegakan sengon buto dekat dengan perairan. Lakitan (2002), menyatakan tinggi rendahnya kelembaban udara di suatu tempat sangat bergantung pada beberapa faktor antara lain: suhu, pergerakan angin, kuantitas dan kualitas penyinaran, vegetasi dan ketersediaan air di suatu tempat (air, tanah dan perairan).

Kelembaban udara terendah pada siang dan sore hari yaitu berada di lapangan sepak bola.Rendahnya kelembaban di lapangan sepak bola disebabkan oleh kondisi RTH pada lokasi ini hanya berupa rumput.Rumput merupakan struktur vegetasi yang biasa digunakan sebagai penutup permukaan tanah.Jika dibandingkan dengan struktur vegetasi yang lainnya, manfaat rumput sebagai pereduksi suhu termasuk dalam kategori yang paling kecil.

\section{Kenyamanan RTH berdasarkan analisis indek suhu dan kelembaban (THI)}

Vegetasi berfungsi sebagai pengendali iklim untuk kenyamanan manusia.Faktor iklim yang mempengaruhi kenyamanan manusia adalah suhu, radiasi sinar matahari, angin, kelembapan, suara dan aroma.Sebagai pengontrol radiasi sinar matahari dan suhu, vegetasi menyerap panas dari pancaran sinar matahari sehingga menurunkan suhu dan iklim mikro (Hakim dan Utomo, 2003).

Berdasarkan kriteria THI dari Wirasasmita (2003), keempat lokasi tersebut menunjukkan keadaan udara pada pagi hari berada pada selang sedang/ cukup nyaman $(<27)$, hal ini diakibatkan radiasi matahari pada pagi hari belum begitu nampak adanya pengembunan sehingga memberikan nilai kenyamanan yang lebih.Peningkatan nilai THI terjadi pada siang hari pada empat lokasi.Ketinggian suhu udara serta kondisi udara yang lebih kering di atas permukaan menyebabkan nilai THI tinggi serta menyebabkan keadaan yang tidak nyaman.

Perubahan nilai THI menurun kembali dalam kondisi sedang/cukup nyaman pada sore hari di lokasi tegakan sengon buto, tegakan campuran dan tegakan beringin.Sementara, lokasi lapangan sepak bolamasih dalam kategori tidak nyaman.Tingginya suhu udara serta kondisi udara yang kering di atas permukaan vegetasi yang berupa rumput menyebabkan nilai THI di lokasi ini tetap tinggi.Pada lokasi vegetasi pohon memiliki nilai THI yang lebih rendah, karena pohon memberikan keteduhan, mengurangi suhu dan radiasi matahari melalui percabangan dan luas tajuk, serta membantu dalam mengalirkan angin.

Tjahyono (2004), menyatakan suhu merupakan faktor iklim yang mempengaruhi kenyamanan manusia. Suhu yang terlalu tinggi atau terlalu rendah akan mengganggu kegiatan manusia. Pada lokasi yang memiliki vegetasi rumput, keadaan udara relatif lebih kering karena kapasitas udar untuk menampung uap air semakin tinggi seiring dengan naiknya suhu udara (Saputro, dkk. 2010).

Perbedaan jenis vegetasi menentukan kondisi iklim mikro pada masing-masing lokasi. Hal ini disebabkan oleh perbedaan karakteristik masing-masing jenis vegetasi dalam menyerap ataupun memantulkan energi matahari yang diterimanya. Menurut Hayati, dkk. (2013), kondisi vegetasi dengan kerapatan pohon yang tinggi dan luas penutupan lahan akan mempengaruhi kondisi iklim mikro (suhu udara dan kelembaban udara), kemudian akan menentukan tingkat kenyamanan berdasarkan nilai THI.

\section{Persepsi responden terhadap kenyamanan dan estetika RTH}

Lapangan sepak bola berdasarkan hasil wawancara menjadi tempat yang paling tidak nyaman dan kurang indah dibandingkan dengan lokasi lain. Hal ini dikarenakan suhu udara di lokasi ini tertinggi bila dibandingkan dengan lokasi lain, sehingga pada lokasi ini paling tidak nyaman untuk beraktifitas pada siang hari. Pada lokasi ini juga kondisi vegetasinya masih kurang memadukan dengan aspek keindahan. Faktor lain yang mempengaruhi 
kenyamanan dan keindahan di lokasi ini adalah fasilitas umum yang kurang mendukung dan kebersihan lingkungan yang kurang diperhatikan. Sementara berdasarkan persepsi responden di lokasi tegakan sengon buto, tegakan beringin dan tegakan campuran termasuk dalam kategori nyaman dan indah.

Kenyamanan di lokasi tegakan sengon buto diduga bukan hanya dari faktor suhu, tetapi dari faktor keindahan dan kebersihan yang mempengaruhi kenyamanan pengguna.Fasilitas tempat berdiskusi dan dekat dengan Perpustakaan Universitas Lampung juga menambah kenyamanan pada lokasi ini.Kemudian lokasi tegakan beringin diduga dipengaruhi oleh luas dan tebal tajuk pohon beringin sebagai peneduh yang memberikan perasaan nyaman bagi pengguna.Selain itu lokasi tegakan beringin didukung dengan kondisi RTH yang dilengkapi dengan fasilitas tempat berdiskusi dan tempat beristirahat yang cukup baik sehingga menambah kesan nyaman dan indah.

Kenyamanan dan keindahan bagi pengguna atau pejalan kaki di lokasi tegakan campuran dipengaruhi kondisi vegetasi yang baik, letak lokasi tegakan campuran juga berdekatan dengan jalur pedestrian. Tajuk yang berada di lokasi ini ada yang menaungi jalur pedestrian, sehingga sinar matahari tidak langsung ke permukaan jalur ini.Kondisi penutupan vegetasi yang rimbun di tiga lokasi memberikan kesan yang nyaman bagi pejalan kaki ataupun pengguna.Zahra, dkk.(2014), mengatakan karakter yang menonjol dari RTH dengan kualitas estetika tinggi dapat memberikan kesan teduh dan nyaman.

Keindahan menurut Hakim (1993), merupakan hal yang perlu diperhatikan sekali dalam penciptaan kenyamanan karena hal tersebut dapat mencakup masalah kepuasan batin dan panca indera. Pemandangan sebagian besar didasarkan pada estetika (buatan manusia) tetapi pada beberapa hal juga berhubungan dengan konservasi.

Menurut Laksmiwati,dkk. (2013), kondisi vegetasi ruang terbuka hijau sangat berpengaruh terhadap kenyamanan dan keindahan bagi pengguna.Kemudian menurut Hakim dan Utomo (2003), keindahan RTH merupakan nilai ruang di luar lahan terbangun yang memiliki karakter terbuka dan terletak di luar massa bangunan, dimanfaatkan untuk kegiatan terbatas dan keperluan khusus.Vegetasi yang tidak terawat dan tidak tersusun juga akan menurunkan keindahan, seperti yang dilaporkan Kaliongga, dkk.(2014), yang meneliti kondisi RTH di sepanjang jalur pedestrian di Kota Medan.

\section{SIMPULAN DAN SARAN}

\section{Simpulan}

Berdasarkan hasil penelitian maka dapat diambil beberapa kesimpulan yaitu.

1. Jenis dan kondisi vegetasi RTH berpengaruh terhadap suhu dan kelembaban udara pada pagi, siang dan sore hari.

2. Tingkat kenyamanan berdasarkan nilai THI pada pagi haridi empat lokasi masuk dalam kategori sedang/cukup nyaman. Kondisi kenyamanan pada siang hari di empat lokasi masuk dalam kategori tidak nyaman. Pada sore hari lokasi tegakan sengon buto, tegakan beringin dan tegakan campuran masuk dalam kategori sedang/cukup nyaman. Sementara, pada lokasi lapangan sepak bola masuk dalam kategori tidak nyaman..

3. Persepsi responden terhadap kenyamanan dan keindahan RTH di lokasi lapangan sepak bola termasuk dalam kategori kurang tidak nyaman dan tidak indah, sedangkan lokasi tegakan sengon buto, tegakan beringin dan tegakan campuran termasuk dalam kategori yang nyaman dan indah.

\section{Saran}

Perlu penambahan pohon di sekeliling lokasi lapangan sepak bola, tegakan sengon buto, tegakan beringin dan tegakan campuran agar menjadi lebih nyaman. 


\section{DAFTAR PUSTAKA}

Arikunto, S. 2011. Prosedur Penelitian Suatu Pendekatan Praktik. Buku.Cipta Karya. Jakarta. $256 \mathrm{p}$.

Gunawan, A. 2005.Evaluasi kualitas estetika lanskap Kota Bogor. Jurnal Lanskap Indonesia.1(1):77-80.

Hakim, R. 1993.Unsur Perancangan dalam Arsitektur Lansekap. Buku.Bumi Aksara. Jakarta. $157 \mathrm{p}$.

Hakim, R. dan H. Utomo. 2003. Komponen Perancangan Arsitektur Lansekap. Prinsip, Unsur dan Aplikasi Desain.Buku. Bumi Aksara. Jakarta. 287 p.

Hayati. J. Santun. R. P. dan Siti. N. 2013. Pengembangan ruang terbuka hijau dengan pendekatan kotahijau di Kota Kandangan.Jurnal Tata Loka. 14(4):306-316.

Kaliongga, F. G. Veronica, A. K. dan Amanda S. 2014. Kajian aspek kenyamanan jalur pedestrian Jl. Piere Tendean di Kota Manado. Jurnal Sabua. 6(2):243-252.

Lakitan, B. 2002.Dasar-Dasar Klimatologi.Buku.PT Raja Grafindo Persada. Jakarta. 189 p.

Lakitan, B. 1993.Dasar-Dasar Fisiologi Tumbuhan.Buku.PT Raja Grafindo Persada. Jakarta. $216 \mathrm{p}$.

Laksmiwati, T. Chairil. B. A. dan Wulan. A. 2013. Evaluasi ruang terbuka di kampus Universitas Brawijaya. Jurnal RUAS. 11(1):334-347.

Saputro, T. D., Indung, S. F., dan Bambang, S. 2010. Studi pengaruh area perkerasan terhadap perubahan suhu udara.Jurnal Lanskap Indonesia.2(2):76-82.

Scudo, G. 2002.Thermal comfort in Greenspace,Proceeding.COST C 11 green structure and urban planning. Milan. Oktober 2002.12 p.

Tauhid.2008. Kajianjarak jangkau efek vegetasi pohon terhadap suhu udara pada siang hari di perkotaan.Tesis. Universitas Diponegoro. Semarang. 126 p.

Tjahyono, B. 2004.Klimatologi.Buku.Pionir Jaya. Bandung. 234 p.

Wirasasmita, M. 2003. Aplikasi Iklim Terhadap Perkembangan Urban, Metropolitan Bandung. Buku.Pusat Pemanfaatan Sains Atmosfer dan Iklim.LAPAN. Bandung. 149pp.

Zahra, A. F. Sitawati dan Agus, S. 2014. Evaluasi keindahan dan kenyamanan ruang terbuka hijau (RTH) Alun-Alun Kota Baru.Jurnal Produksi Tanaman. 2(7):524-532. 